\title{
Article
}

\section{Social work in the public services in Brazil - disclosing ruling relations in a local context}

by

Trond Heitmann

PhD Candidate

Østfold University College

P.O. Box 700, 1757 Halden, Norway

Tel.: +47474010 15/69215000

E-mail: trond.heitmann@hiof.no

\section{Keywords:}

professional social work, professional practice, Brazil, institutional ethnography, social construction

\section{(c) (†) (2)}

This work is licensed under a Creative Commons Attribution-ShareAlike 4.0 International License. 


\begin{abstract}
This article about social workers in the public social services in Brazil explores professional social work practice through the subjective standpoint of the social workers. Inspired by institutional ethnography, this approach explicates how understandings of social work are interpreted and implemented in various contexts. The findings show that the formalization of the relationship with the employer through contracts of employment implicate that the disciplinary normative definitions of social work succumb to institutional regulations, which are not necessarily discipline specific. In addition, the temporary character of the contracts of employment makes the social workers align their practice to institutional frameworks and demands, as they are personally interested in renewal of the contracts and the maintenance of their professional careers. With this approach, disciplinary, political, ideological, legal and moral definitions of social work are not viewed as the essences of social work, but rather as contextual processes that are locally activated in different contexts. At the same time, it underscores social work as a political profession which should naturally include interventions on political, juridical, economic and organizational levels. Consequently, professional social work is not one thing, nor only one profession, but rather professional practices adapted to a variation of contexts. This perspective is significant to help detect areas of intervention for social change.
\end{abstract}

\title{
Keywords:
}

professional social work, professional practice, Brazil, institutional ethnography, social construction 


\section{Social work and contexts}

While professional social work is clearly a concept which is considered as relevant and meaningful across different societies, it is also an unruly concept that is difficult, if not even impossible, to encompass and define with universal applicability. Some point to a common core of social work (Weiss, 2005), or that in all its shades and variations, social work is usually based on common values and principles (Asquith, Clark, \& Waterhouse, 2005; Payne, 2014). The two international bodies of social work, the International Federation of Social workers (IFSW) and the International Association of Schools of Social Work (IASSW), have developed a common global definition of social work, but there are disagreements and diverse perceptions of the definition itself, as well as the meanings associated with different concepts in the definition (CFESS, 2011; Hare, 2004; Truell, 2014). The implication of this is that it is not given what to encompass as social work, and consequently, when doing research on social work the object of study is not given either. It changes and is adapted to different contexts where different social, historical, economic and political processes, combined with various subjective positions, construct the significance of social work differently (Lyons, 2012; Payne, 2006; Smith, 2005).

This article proposes an approach to research on social work practice that emphasizes the exploration of contexts, in order to disclose how professional social work practices are coordinated. In this, special attention is directed to the relations of employment which define the individuals as professionals and their scope of professional conduct. An epistemological basis for the research is that social work is based in both a disciplinary field of knowledge, and in professional practices aiming at social change (IFSW, 2014; Payne, 2006). These two dimensions of professional social work, which are interdependent and justified by each other (Dellgran \& Höjer, 2012), also represent considerable tensions between professional ideology and knowledge on the one side, and the various terms of the provision of social assistance on the other (Carey, 2014; Françozo \& Cassorla, 2004; Lipsky, 2010 [1980]; Mota, 2013). The explication of various contexts emphasize social work as socially constructed, articulated, negotiated and contested in interactions between people (Payne, 2006).

On a macro-level, various interpretations of the aim and purpose of social assistance formulate policies, organize the provision of services and articulate laws based on 
political views, norms and values. When the services of social assistance are provided through communication between professionals and the citizens situated in different contexts, these incentives are in turn interpreted, adapted and modified on different micro-levels by various people defining meanings, and consequently adequate actions in these different contexts (Lipsky, 2010 [1980]). The research on which this article is based focuses on the interpretations and experiences of the professional social workers. Through this bottom-up perspective, professional social work is encompassed by an emphasis on descriptive definitions, putting weight on the necessity to explore contexts in order to enhance the understandings of professional practice. This makes it possible to disclose relations that are actually significant in a specific context, providing valuable insights in understanding how local contexts are connected in different ways to a wider web of relations that influence interventions for social change. Inquiring into locally contextual dimensions of social work therefore gives valuable contributions to help understand how social work practices are conducted differently in different contexts, providing important feedback to professionals, politicians and administrators in the development and implementation of social assistance.

\section{Social work in Brazil}

The empirical data in this research is produced through interviews and participant observation among social workers serving in urban low-income neighbourhoods in the urban municipality of Vitória in southeastern Brazil. In Brazil, as in Latin-America in general, social work is associated with a field of knowledge influenced by critical social work and inspired by Marxist interpretations of social relations, a perspective that has been particularly emphasized in the development of social work as an academic field (lamamoto \& Carvalho, 1982 [2014]; Montaño, 2012; Saracostti, Reininger, \& Parada, 2012). Emphasizing social work as an autonomous field of knowledge, and not subjected to different government policies and salaried employment, social work knowledge in Brazil is commonly referred to as social service, while the interventions guided and influenced by different political ideologies and the organization of social security, both within and beyond the discipline of social work, are termed social assistance (CFESS, 2005; Mota, 2013). The aspect of work, understood as the exchange of liberty for salary in the marketplace is in other words mitigated, making the concept of social work not directly applicable in Brazilian contexts (Mota, 2013). 
Still, for analytical purposes, in this text the term social work is applied to include both the discipline and the professional practices and for reasons I will explain later; in this article, professionals involved in social work are described as social workers, also including when their professional education is within other disciplines.

Professionals educated in the professional field of knowledge of social work, referred to as social service in Brazil, are designated as social assistants. According to the Federal Council of Social Service (CFESS), ${ }^{1}$ there are 160,000 registered social assistants throughout Brazil, which in numbers is exceeded only by the United States. To work as a social assistant requires a lower-grade university graduation in social service and an affiliation with the Federal/Regional Council of Social Service (CFESSCRESS). ${ }^{2}$ The first social assistants in Brazil graduated in 1938, and the profession has been regulated as a profession since 1962. In public policies and education and academic research, there is a strong focus on cross-sectorial and cross-professional collaboration (Saracostti et al., 2012), and several other professions such as pedagogy and psychology are included in the provisioning of social assistance (CNAS, 2011).

Public social assistance in Brazil is organized under what is called the Unified Social Assistance System (SUAS), which employs 330,000 professionals ${ }^{3}$ (Portal Brasil, 2017). Through the SUAS, there are three defined levels of attention: basic assistance, assistance of medium complexity and assistance of high complexity (MDS, 2004).

Basic assistance is provided through the Reference Centre for Social Assistance (CRAS), ${ }^{4}$ which is located in a defined territory, serving the neighbourhoods that are geographically close to the centre. With the responsibility of executing the national Programme for Integrated Family Attention (PAIF), ${ }^{5}$ they employ various supportive and preventive measures, including regular follow-up of families, collective and community focused activities and the provision of different social benefits, aiming at reducing risk and strengthening family- and community ties. The second level of attention is defined as medium complexity, which is attended to by Reference Centres for Special Social Assistance (CREAS), ${ }^{6}$ providing protection and assistance in situations of immediate concern defined as threatening to rights and the well-being of the individuals. This could include situations of neglect, the follow-up of juvenile delinquency, threats of physical, psychological or sexual violence, various types of exploitation and other 
problems needing special attention or intervention. The CREAS is like the CRAS, working within the context of the family and the community, and is responsible for a defined territory that usually covers the responsibility of a given number of CRASs. The third level of attention, situations of high complexity, provides protection and assistance in cases where the citizens need to be separated from the community or family. This is typically a wide range of institutional care addressing various situations where community and family ties are broken, severely weakened or even representing threats to individuals or families.

The organization of the SUAS is a municipal responsibility and implies collaboration with the civil society and a wide range of public entities and stakeholders in the welfare services, such as health services, the legal system, voluntarily non-governmental organizations (NGOs) and various private actors, providing social services in collaboration with the municipality. The extensive collaboration with civil society, NGOs and private actors, referred to as the network of social assistance, is an essential aspect of the organization of social assistance both in Vitória and in Brazil at large. These forms of collaboration are organized in formal partnerships in the provision of services, and through collaboration with voluntarily organizations that provide supplementary services (J. R. Lopes, 2004; Lopez, de Souza Leão, \& Grangeia, 2011; Silva, 2010).

\section{Analytical approach}

To understand how the professionals interpret and experience social work practice, the research in this article explores what social workers in the basic services do, and which relations they subjectively report as decisive for their actions. Their experiences and interpretations are in turn investigated to disclose the positioning of the social workers and their connectedness to processes in society that organize and orchestrate the task, responsibilities and doings of the social workers. Thus, the research approaches social work through a descriptive perspective, rather than a normative or essentialist perspective.

This analytical perspective is indebted to the sociological approach known as institutional ethnography (Smith, 2005). In some aspects it resembles the traditions of grounded theory, in which empirical induction forms the basis for theory-building 
(Glaser \& Strauss, 1967). But where grounded theory tends to claim that theory is developed only in relation to the observed empirical material, this study emphasizes the local data as expressions of processes that exist beyond the observed context (Smith, 2005). The approach is therefore on one side concerned with analysing the data without putting on a theoretical macro-oriented straitjacket that structures and interprets the subjective accounts and experiences of the informants. On the other side, to disclose the web of social relations that influence social work practice, the analysis goes beyond the social context where the data is produced, and explores their connectedness to larger processes of coordination of activities.

A central concept in this approach is the concept of ruling relations. This refers to how knowledge becomes objectified and standardized, and with the help of different technologies, employed as important and increasingly effective vehicles for ruling (Campbell \& Gregor, 2008). Adapted to the case in this study, the activities of the social workers are coordinated through such objectivized systems of knowledge such as text documents, laws, norms and discourses (Campbell \& Gregor, 2008) that originate outside the empirical context under study. They are referred to as translocal (Smith, 2005) in the sense that they 'pass through local settings and shape them according to a dynamic of transformation that begins and gathers speed somewhere else' (DeVault \& McCoy, 2006). In institutional ethnography, attention is directed to how this is expressed locally by people who are subjectively placed in a web of social relations influencing their everyday practices. With this, it is not ruling relations as nominal influences that draw the interest of the researcher, but how they are activated locally and actually direct people's actions (Campbell \& Gregor, 2008).

The undertaking of the researcher is to explore the social relations that guide and coordinate the actions of the social workers as they are expressed, experienced and interpreted by actual people locally. (Smith, 2005). In the first level of investigation, the focus is on the local context, or 'entry-data' (Campbell \& Gregor, 2008; DeVault \& McCoy, 2006). This is where the translocal ruling relations are activated, and coordinate professional practice that serve as entry points to the process of research. These expressions and their connection to a wider field of institutional processes are then explored and disclosed, leading to the investigation of 'level-two data' (Campbell 
\& Gregor, 2008; DeVault \& McCoy, 2006), in which relations of ruling are explicated as standardized forms that replicate and organize knowledge and social relations.

As mentioned above, there are several layers of interpretation and translation adapting the normative regulations to various contexts. The normative and ideological perceptions of social work might be important, but individuals or collectives act in relation to ruling relations in different ways and the different experiences depend on the local and subjective standpoint of the actors. Therefore, potential relations of ruling, and of coordinating activities, must be explored through research that discloses the subjectively experienced context as described by the professionals, and not defined a priori as described by the researcher. This act of knitting together and translating the locally observed to the translocal ruling relations defies the micro and macro perspectives as dichotomies. Consequently, because the translocal processes are relevant to the extent that they are disclosed as locally active and significant, the research starts with what people know about their everyday work, as opposed to what others hold to be the aim and purpose of the work of the professionals (Smith, 2005).

\section{Methods of data production}

The research started from observing, accompanying and interviewing the professionals, including the coordinator at one of the CRAS. Through the production of data in this particular CRAS, referred to above as 'entry-data' (Campbell \& Gregor, 2008), various references of ruling relations emerged, directing attention to translocal processes and social relations originating outside the immediate local context of the CRAS.

The other level of data collection, 'level-two data' (Campbell \& Gregor, 2008), involved various actors related to the social workers at the CRAS. Because the professionals under study were working extensively with professionals at voluntary NGOs in the neighbourhood, two weeks were spent at a nearby NGO, following their daily practices and routines, as well as interviewing professionals and one administrative leader. Also, some time was spent at another CRAS in another neighbourhood, observing counselling with clients and interviewing some of the professionals and the coordinator. In addition to this, conversations and interviews with key leaders in the municipal administration were also undertaken. This was helpful, as they were situated closer to 
the administrative, economic, political and legal frameworks influencing the work of the professional social workers. Several of the families attended by the CRAS were also accompanied by the CREAS (the second level of attention in the SUAS), and observation and interviews were made with professionals at the CREAS. Starting with the CRAS and the eight professionals working there, the collection of data involved a total of 12 professionals employed at two different CRAS, three professionals working at a CREAS and three administrative leaders of municipal services. In addition to representatives in the public services, four professionals in the NGO collaborating with the CRAS were interviewed. I also interviewed a retired social assistant who had worked for a NGO in the same neighbourhood where the research was undertaken, and the director of the state-level Adventist Development and Relief Agency (ADRA), which provides social services in partnership with the municipality of Vitória. At the end of the data collection, focus group interviews were conducted twice with the eight professionals at the CRAS and once with the professionals at the nearby NGO, in order to be able to contrast the individual interviews with discourses in collective contexts. Laws and orientations, regular reporting and registrations, assessments, contracts, computer software, and several other processes of condensing and transmitting information which standardized the work of the professionals, were also investigated in producing 'level-two data'.

A total of 27 interviews were conducted with 24 individuals, with the research carried out during a period of six months from October 2014 to April 2015. All the interviews and field notes were digitalized using the software QSR Nvivo 10 to identify communalities and relationships between various observations and expressions. Different written documents issued by the authorities on both the municipal and federal level were also read and included in the software. The digitalization was not done as a tool for analysis, but instead to establish a manageable overview over the data (DeVault \& McCoy, 2006). The research was approved by the Ethical Committee of Research at the Pontifical Catholic University of Rio de Janeiro and the research council at the secretary of social assistance in the municipality of Vitória.

\section{Ruling relations encompassing the social professions}

Most of the professionals in the basic social assistance services in this study were social assistants by education, but there were also other professionals educated as 
pedagogues, psychologists or physical educators. In formal descriptions of the minimum requirements for professional staff at the CRAS, it is mandatory to include a defined number of social assistants depending on the size of the population attended to by the CRAS. There is also a preference for including at least one psychologist at every centre, and when it comes to CRASs that serve a population of more than 5,000 families, employing a psychologist is mandatory (MDS, 2004). In addition to this, the municipal government of Vitória defined anthropology, domestic economy, pedagogy, sociology, rehabilitation therapy and music therapy as qualifying disciplines for being a social worker (PMV, 2014). Of the 24 interviewees, 16 were educated as social assistants, four were psychologists, two were pedagogues, one was a physical educator and the director of the ADRA was a theologian. Of those, 19 were working directly with the citizens in providing social assistance, including the psychologists, pedagogues and the physical educator and 12 social assistants.

Therefore, exploring social work practices at the CRAS requires an ample and inclusive approach to the understanding of social work practice that goes beyond the established discourses of separate professional disciplines. The tasks of the CRAS are performed by professionals from different disciplines represented by what can be called as 'an umbrella of social professions' (van Ewijk, 2009, p. 168). The role of various disciplines at the CRAS is addressed in the public policies (MDS, 2009), as well as being a matter of concern in academic discourses constructing social work in Brazil (R. E. Lopes \& Malfitano, 2006; Quintino, de Mattos, Barbosa, \& Forster, 2012). At the same time, several studies show that the role and tasks of the various professions in the SUAS are not as clear-cut when it comes to practical implementation (Costa \& Cardoso, 2010; Françozo \& Cassorla, 2004). Hence, social worker is an inclusive term that applies to all contracted as professionals at the CRAS independent of their professional education. For this reason, the significance of the different professions cannot be taken as given as a ruling relation in the provisioning of social assistance, but should instead be explored in the local contexts where the professional practices are taking place.

At the CRAS in this study, the tasks and responsibilities were not defined as actions divided by disciplinary competence, and the disciplinary differences were not reflected as decisive in objective standardizations of how to organize the work at the CRAS. 
The disciplinary variation represented a potential to interpret various problems and their solutions differently, thereby contributing to a heterogeneity of knowledge within the team of professionals at the CRAS. This was illustrated by one psychologist, who was asked about what they do in their everyday work:

Within the social services of assistance, especially in the basic services of the CRAS, the role of the psychologist does not differ from the social assistant. There are no differences in the actions, only that my glance as a psychologist is different from that of the social assistant.

From the standpoint of the professionals at the CRAS, the separation between the various professions did not pose significant any differences in their daily work. In general, their experience was that they perform the same tasks, were using the same uniforms and were recognized as social workers by the population with whom they interacted. In practice, the disciplinary approach was articulated in vague terms as defining a 'glance', and they reported that it was not obvious how their tasks were different from that of other professional disciplines employed at the CRAS. This is not to say that they were not concerned about how the various disciplines represented at the CRAS should interact, but it is important to emphasize that different disciplines were neither a formal nor given organizing principle for the services and designation of tasks.

The intention of drawing attention to how professional practice includes various social professions is twofold. One is a matter of explaining empirical context, namely that this study of social workers at the CRAS includes people who are trained in various professions. The analysis must therefore incorporate this aspect. This implies that it is important to avoid making distinctions in professional practice based on the construction of professional disciplines that are constructed elsewhere, such as in government orientations or academic research areas that that do not necessarily coincide with local practice.

The other is to draw attention to the ruling relations directing the activity of the professionals and the implications of how social work professional practice is organized. Legal and formal regulations coordinate various disciplinary knowledge (social work, psychology, pedagogics, etc.) into what becomes practices, thus mitigating the influence of disciplinary variations. This implies that social work practice 
in the CRAS is subjected to the adaption of bureaucratic means to help provide social services, and not primary in terms of normative definitions of one academic or professional discipline. By applying perspectives that disclose ruling relations as those that are actually locally active through the standpoint of the professionals, what is disclosed is not an interaction between disciplines pre-defined by the researcher. Instead, it is how these disciplines are subsumed under a common practice defined by detailed descriptions of how to conduct the tasks at the CRAS.

In this sense, social work is created in the daily work of the professionals, which includes different disciplines and organizational structures that do not necessarily coincide with one academic field of research or profession. Research must integrate this in order to grasp the social reality of the researched, and not first and foremost postulate a replication of the social reality of the researcher, the labour unions or the government documents that emphasize the differences between professions. Therefore, the researcher does not 'identify a position or a category of position, gender, class, or race within the society' prior to the research, but rather 'establish[es] as a subject position (...) as a method of inquiry, a site for the knower that is open to anyone' (Smith, 2005, p. 9), in order to explicate the locally constructed meanings of, e.g., social work. In this respect, the researcher takes the perspective of the professionals (the knowers) to disclose dimensions of understanding of how their work is coordinated and organized. And from this perspective, social policies articulated in formal reporting systems, standardized and quantified descriptions of their tasks and responsibilities, the structuring of information, organizational requirements, or what can be lumped together as the policies and the bureaucracy of the social services, make the professionals describe their work as ruled by similar relations independent of their professional affiliations. This is not to say that professional knowledge or professional ethical conduct is not relevant at all. In communication and collaboration between colleagues, the different knowledge contributed to various perspectives in problem solving, but as I will discuss in the next section, the disciplinary knowledge is disciplined by formal organizational and bureaucratic structures.

\section{Ruling relations formalizing the subjects as social workers}

The formal contract of employment was essential as a link between the social workers representing different professions and the execution of professional practice. This is 
what made them social workers, and without the contracts, they had no legitimate role in the services of social assistance.

The public social workers in this study worked under two kinds of contracts: one was as workers directly contracted by the municipality of Vitória and the other was as workers contracted by the international religious NGO, the Adventist Development and Relief Agency (ADRA), which was running the CRAS in partnership agreements with the municipality. In conversations with municipal administrative authorities, they viewed partnership agreements with NGOs such as the ADRA as a necessary measure to implement social policies, since federal regulations limited the municipal direct expenditures on wages. ${ }^{7}$ From the position of the social workers, the different contracts meant some variations in working hours, salaries, and different regulations regarding holidays and fringe benefits, but when it came to daily work, all were working under the same regulations, organization and procedures.

Most importantly, in both types of contracts, the formal connection between the social workers and the public services was unpredictable and insecure. Of those contracted directly by the municipality, and who did not have any responsibilities as coordinators, all were on three-year contracts or employed as a part of temporary projects. In the case of the workers employed by the ADRA, their job was depending on the partnership agreement with the municipality. These agreements had to be renegotiated every year, which is usually only a formality, but they were never renewed for more than five subsequent years when a new tender had to be announced. The ADRA could also change their spheres of interest or projects, reallocate their employees or refrain from renegotiating the agreements. This meant that social workers knew their current job had to be regularly renegotiated, and could not expect that they could maintain the same duties and responsibilities and could be dismissed if the partnership agreements were not renewed. To the social workers, indifferent to what kind of contract was linking them to the professional services, the duration of the contracts and the connection between the professionals and the social services were pre-defined as temporal.

As a result, the social workers opted for improving and securing their job relations, and were concerned with recurrent and active career planning. When asked about their future professional prospects, one social worker replied: 
I do not know if I can stay at the CRAS. The job marked does not allow it, you know. (...) With the municipality you have a determined contract for maybe two years. After this, you are not with the municipality anymore.

The contracts with the ADRA did not define an expiration date, which made some professionals opt for a contract with the ADRA rather than the municipality. As another social worker commented:

I entered (the CRAS) as contracted by the municipality. (...) But then I got the possibility to change (...) so, before my contract with the municipality expired I got the chance to change to a private company. (...) Everyone wants to work for the ADRA $(\ldots)$ it gives more security. ${ }^{8}$

The temporal character of the contracts makes the professionals view their work in terms of states of future stability, as they know that more sooner than later they will need to find new employment. They were not only social workers in the present, but also future job-seekers, often submitting their job applications to the same employer. And most fundamentally, to the professionals, professional social work is a breadwinning activity.

Like social workers and first-line public servants in other parts of the world, their moral considerations based in professional knowledge were frequently challenged or even undermined by bureaucratic proceedings and legal regulations (da Silva, da Fonseca, \& Mello, 2009; Lipsky, 2010 [1980]). The manoeuvrability to exercise professional discretion that breaks fundamentally with the bureaucratic institutionalization of social policies was discouraged by the fact that the social workers were on temporary contracts, which in turn highlighted the need to include their personal career as an interpretative aspect of their professional conduct. Even though most professionals said that from time to time they broke some rules or norms in order to act in a morally and professionally acceptable way, in general there was much attention directed towards maintaining the limits of public services. Consequently, the concept of assisting and orienting clients within the confinements of law and resources set by the government were fundamental to the perception of acting as a professional.

This is not to say that the social workers did not reflect on the shortcomings of public services. Nevertheless, being too critical or using professional discretion to jeopardize 
the integrity and credibility of public services could imply personal risk. One of the municipal administrative leaders underscored things in this ways:

What happens? Everyone is on temporary contracts, so nobody is encouraged to fight to improve the system, because nobody wants to lose their contract. Everyone needs it. And then the political engagement gets weak.

To summarize, the ruling relations that formalize and define the subjects as professionals are perceived as unstable and unpredictable, which subsequently promotes a culture of loyalty towards the bureaucratic demands when it comes to professional conduct. A ceaseless state of career planning and improvement of their future employment prospects was a constant concern for most of the professionals. At the time of the research, only one out of eight social workers at the CRAS had worked in their current positions more than two years, and on a brief visit half a year after the field research all of the professionals at the CRAS had left for other positions. Unless there are fundamental changes on political, managerial or organizational levels, the social workers in the public services need to exercise their discretion within the confinements of an unstable connection with their employer.

\section{Non-governmental assistance as a comparative example}

To emphasize the significance of the ruling relations of employment, it is useful to reflect on the differences between professionals at the CRAS, and professionals in collaborating entities working with the CRAS on the level of basic social assistance. One of these was the São Francisco Institute ${ }^{9}$ an NGO working with children and their families, providing after-school activities within sports and culture and the following-up of families. The institute participated in various forms of collaboration with other public and private entities on the community and municipal levels, and they had frequent communication with the CRAS in relation to both specific cases and general incentives within the community. This was not a formal contractual relationship, but a voluntarily collaboration acknowledging that both entities were working to achieve common aims in the same community. Like the CRAS, the São Francisco Institute employed professional social workers: a social assistant, a psychologist and a pedagogue. These professionals did not work on temporary contracts, and had been in their positions for several years at the time at the fieldwork. 
Working with basic services in the same neighbourhood, the CRAS and São Francisco Institute often assisted the same families, but different processes and managements ruled their professional roles. Non-governmental social services do not need to offer services of universal accessibility, and are less likely to be ruled by elaborate bureaucratic regulations which are necessary in public services in order to protect universal rights and equality (Corry, 2010; Etzioni, 1996; J. R. Lopes, 2004; Murphy, 2010). Working in conditions of less detailed bureaucratic ruling, a higher degree of responsibility were put on the professionals employed by the institute to organize and develop interventions of social assistance. Consequently, the professionals reported more liberty to exercise professional discretion and organize their own work to meet the actual needs of the citizens compared to their colleagues in the public services. Or as expressed by one of the professionals: 'We are the ones crating the bureaucracies here.'

The different contexts of execution of social assistance are not only limited to acknowledging different organizational affiliations, but also raise questions about the moralities and values in social work. Characteristically, emphasizing the rigid regimes, limited resources and understaffed public services, one of the professionals at the São Francisco Institute said that:

I do not think they (the public services) take responsibility for social follow-up (...) to see the child, see them in their eyes every day to know whether the child is at peace needing attendance or not (...) this is difficult with our number of children. Imagine doing this (one person) circulating in three places, each with two or three times the number of children that we attend.

Thus, the apparent differences between the basic social assistance of the NGO and the CRAS are expressed as differences in moralities and views on core values of social work. However, what this research emphasizes is that these differences are not necessarily based on different perceptions of social work, but rather on different contexts that organize relations of employment differently, and consequently the relations that rule professional practices.

Because the services of the São Francisco Institute were not statuary, the professionals were given the responsibility to develop their own guidelines and procedures. In addition, since they were not guided by the laws of rights to assistance, nor financed by public funding, as they could also insist on providing the services with 
a higher quality compared to public services. The alternative to insufficient budgets was not to downscale the services in terms of quantity or quality in order to observe the universal access to social assistance that often happened in public services, but rather to close down the institute all together, ${ }^{10}$ In this way, the reportedly wider scope for professional discretion depended on private funding, limitation of the target population and the maintenance of a high quality of the services. In short, the context of organizing professional interventions in social assistance was different.

\section{Conclusion}

The fundamental inference to be drawn from this study, and the analytical perspectives of institutional ethnography, is that the relations of employment is a crucial field to investigate to help disclose confinements, possibilities and obstacles, i.e., the contexts that influence social work practice.

In the case of public social assistance at the CRAS, the temporal nature of the contracts of employment and the constant state of career planning was an essential aspect of the professional practices, leading to a loyalty towards bureaucratic regulations, sometimes at the expense of disciplinary discretion. This is not the same as claiming that the bureaucracy of the public services undermines social assistance. Rather the contrary, the bureaucratic organization of social assistance is necessary and fundamental in guaranteeing universal access to social assistance. Still, in the public services of the CRAS, the various processes standardizing practices are directing and confining the space for professional discretion, and combined with the desire to maintain and continue the unstable relations of employment, the social workers remain largely loyal to bureaucratic regulations. Looking to the professionals in the NGO, their services are limited and not statuary, less ruled by translocal bureaucracies regulating the actions of interventions, and the professionals are contracted without pre-defining when the working relationship expires. These different relationships of employment are significant variables ruling the scope of professional discretion and the provision of social assistance.

Another inference to be drawn from this study is that interventions for social change are not limited to implementing local incentives of social assistance. Outlining the significance of employment relationships, the study invites social work professionals 
and academics to contribute to changing contexts confining the execution of social assistance. This implies that social work has a profound political dimension that goes beyond the immediate local relations between professionals and citizens. Extending the scope of social work practice and knowledge to include interventions in the political, juridical, economic and organizational levels discloses how contexts are significant beyond the immediate social context of the families and individuals receiving social assistance. Social assistance is not provided in a state of political or bureaucratic neutrality, as the role and mission of social work professionals and academics are as important on the levels of politics and management as on the level of implementing social policies. Facilitating participation in influencing the contexts of social assistance as a part of the tasks and responsibilities of professionals could contribute to improved services.

The article also calls for further investigation. As mentioned in the introduction, social assistance in Brazil is deeply concerned with inter-sectional and cross-professional collaboration, and is provided through a network of various stakeholders representing the governmental, private and civil sectors. Therefore, how professionals interact with other professionals in representing different organizational affiliations and different relations of employment could yield further insight into how the professionals are guided by a totality of social assistance services. In turn, this could provide a fuller picture of the various fields of intervention, focusing more on the creativity of the social workers and their coping strategies, while disclosing how the professionals interpret their role in differe nt contexts within a wider web of connections between people and management. 


\section{End notes}

1. Conselho Federal de Serviço Social

2. Conselho Federal de Serviço Social- Conselho Regional de Serviço Social

3. In addition, 272,000 work in administrative positions.

4. Centro de Referência de Assistência Social

5. Programa de Atenção Integral à Família

6. Centro de Referência Especial de Assistência Social

7. Law of Financial Responsibility/ Complementary Law 101/00 section II, article 19. This is also a result of a neo-liberal influences on the provision of welfare.

8. It was difficult to know whether the social workers in general favoured one contract over the other. When asked, they tended to focus on the advantages of their current employment contract.

9. Not the actual name of the institute.

10. At the time of the research, the public services were downscaling their services due to economic recession and political instability. Likewise, several prominent NGOs like the Ação Comunitária do Espírito Santo in Vitória closed down, as they lost funding from private donors hit by financial difficulties. 


\section{References}

Asquith, S., Clark, C., \& Waterhouse, L. (2005). The role of the social worker in the 21st century: A literature review. Edinburgh Retrieved from http://www.gov.scot/resource/doc/47121/0020821.pdf.

Campbell, M., \& Gregor, F. (2008). Mapping social relations: A primer in doing institutional ethnography. Toronto: University of Toronto Press.

Carey, M. (2014). Mind the Gaps: Understanding the Rise and Implications of Different Types of Cynicism within Statutory Social Work. British Journal of Social Work, 44(1), 127-144. doi:10.1093/bjsw/bcs098

CFESS (2005). Serviço Social é Profissão. Assistência Social é Política Pública. In Conselho Federal de Serviço Social (Ed.), CFESS Manifesta (Vol. December 2005).

CFESS (2011). Prelimenary Draft for the Workshop on the IFSW Global Definition of Social Work. Retrieved from http://www.cfess.org.br/arquivos/text_eng.pdf CNAS (2011). Resolução no. 17 de 20 junho 2011. In Conselho Nacional de Assistência Social (Ed.).

Corry, O. (2010). Defining and Theorizing the Third Sector. In R. Taylor (Ed.), Third Sector Research (pp. 11-20). New York, NY: Springer New York.

Costa, A. F. d. S., \& Cardoso, C. L. (2010). Inserção do Psicólogo em Centros de Referência de Assistência Social. Revista Interinstitucional de Psicologia, 3(2), 223-229.

da Silva, V. R., da Fonseca, F. F., \& Mello, R. (2009). Atuação profissional no SUAS: Desafios e possibilidades para os assistentes sociais. Sociedade em Debate, 15(1), 135-146.

Dellgran, P., \& Höjer, S. (2012). The politics of social work research-Ph.D. theses in Sweden. European Journal of Social Work, 15(4), 581-597. doi:10.1080/13691457.2012.710875

DeVault, M., \& McCoy, L. (2006). Institutional Ethnography: Using interviews to investigate ruling relations. In D. E. Smith (Ed.), Institutional ethnography as practice (pp. 15-44). Lanham, Md: Rowman \& Littlefield.

Etzioni, A. (1996). The new golden rule: Community and morality in a democratic society. New York: Basic Books. 
Françozo, M. d. F. d. C., \& Cassorla, R. M. S. (2004). Rewards and Frustrations of Being a Social Worker: A Qualitative Study. Journal of Social Work Practice, 18(2), 211-221. doi:10.1080/0265053042000231025

Glaser, B. G., \& Strauss, A. L. (1967). The discovery of grounded theory: Strategies for qualitative research. Chicago: Aldine.

Hare, I. (2004). Defining Social Work for the 21st Century: The International Federation of Social Workers' Revised Definition of Social Work. International Social Work, 47(3), 407-424. doi:10.1177/0020872804043973

lamamoto, M., \& Carvalho, R. d. (1982 [2014]). Relações sociais e serviço social no Brasil - esboço de uma interpretação histórico-metodológica (40 ed.). São Paulo: Cortez Editora.

IFSW (2014, July 2014). Global Definition of Social Work. Policies. Retrieved from http://ifsw.org/policies/definition-of-social-work/

Lipsky, M. (2010 [1980]). Street-level bureaucracy: Dilemmas of the individual in public services (30th anniversary expanded ed.). New York: Russell Sage Foundation.

Lopes, J. R. (2004). Terceiro setor: A organização das políticas sociais e a nova esfera pública. [Third sector: The organization of social policies and the new public sphere ]. São Paulo em Perspetiva, 18(3), 57-66.

Lopes, R. E., \& Malfitano, A. P. S. (2006). Ação social e intersetorialidade: Relato de uma experiência na interface entre saúde, educação e cultura. [Social work and intersectionality: Accounts of an experience in the interface between health, education and culture]. Interface - Comunicação, Saúde, Educação, 10(20), 505-515.

Lopez, F. G., de Souza Leão, L., \& Grangeia, M. L. (2011). State, Third Sector, and the Political Sphere in Brazil. International Journal of Sociology, 41(2), 50-73. doi:10.2753/IJS0020-7659410203

Lyons, K. (2012). The SAGE Handbook of International Social Work. London: SAGE Publications Ltd.

MDS (2004). Política nacional de assistência social/ Norma Operacional Básica. Brasília.

MDS (2009). Norma Operacional Básica de Recursos Humanos do Sistema Único de Assistência Social- NOB-RH/SUAS. Brasília. 
Montaño, C. (2012). Social work theory- practice relationship: Challenges to overcoming positivist and postmodern fragmentation. International Social Work, 55(3), 306-319. doi:10.1177/0020872812437226

Mota, A. E. (2013). Serviço Social brasileiro: Profissão e área do conhecimento. Revista Katálysis, 16, 17-27.

Murphy, J. (2010). The Dark Side. In R. Taylor (Ed.), Third Sector Research. New York: Springer.

Payne, M. (2006). What is Professional Social Work? Chicago: Lyceum Books Inc. Payne, M. (2014). Modern social work theory (4th ed.). Basingstoke: Palgrave Macmillan.

PMV (2014). Gerência de atenção à família. Vitória.

Portal Brasil (2017). Sistema Único de Assistência Social reforçou profissionalização no setor. Retrieved from http://www.brasil.gov.br/cidadania-ejustica/2016/05/implantacao-do-suas-reforcou-profissionalizacao-naassistencia-social

Quintino, T. D., de Mattos, A. T. R., Barbosa, D. C. M., \& Forster, A. C. (2012). As contribuições do assistente social no campo da promoção da saúde: Desafios e possibilidades. [The contributions of the social worker in the field of health promotion: Challenges and opportunities]. Revista de Atenção Primária à Saúde, 15(3), 345-355.

Saracostti, M., Reininger, T., \& Parada, H. (2012). Social Work in Latin America. In K. Lyons (Ed.), The SAGE Handbook of International Social Work (pp. 466479). London: SAGE Publications Ltd.

Silva, C. E. G. (2010). Gestão, legislação e fontes de recursos no terceiro setor brasileiro: Uma perspectiva histórica. [Management, legislation and funding sources in the Brazilian third sector: A historical perspective]. Revista de Administração Publica, 44(6), 1301-1325.

Smith, D. E. (2005). Institutional ethnography: A sociology for people. Lanham, Md: AltaMira.

Truell, R. (2014). Report to the IFSW general meeting on the review of the global definition of social work. Retrieved from http://cdn.ifsw.org/assets/ifsw_94359-2.pdf

van Ewijk, H. (2009). Citizenship-based social work. International Social Work, 52(2), 167-179. doi:10.1177/0020872808099728 
Journal of Comparative Social Work 2017/2

Weiss, I. (2005). Is There a Global Common Core to Social Work? A Cross-National Comparative 